\title{
TOWARDS CREATION OF A UNIFIED INFORMATION SYSTEM OF THE NAVIES OF THE BLACK SEA COUNTRIES ${ }^{1}$
}

\author{
Peter PETROV
}

\section{Security environment and non-traditional challenges}

The particular geostrategic position of the Black Sea in the transeuropean lines of communications and the national systems of transport, the availability of certain stocks of fish, petrol, gas and other natural resources determine the set of factors and often controversial interests exerting strong influence not only on sea navigation, but also on the security of the whole region.

\section{External political factors}

During the last years, external political factors have a prevailingly positive effect on strengthening the common security in the region. Although slowly, the confrontation model of international relations is replaced by a new model characterized my mutual cooperation that includes organization of future mutual activities. Inseparable parts of this model are the activities aimed at the organization and control of the navigation in the region. Main components of this regime are:

- Control over maritime traffic and economic activities at sea;

- Safety of navigation;

- Seamless functioning of the traffic control infrastructure;

- $\quad$ Rescuing human life at sea;

- Protection of maritime environment;

- Prevention of breaks of law and law enforcement, etc.

\section{Economic factors}

In terms of economics, we anticipate increase of the importance of the Black Sea and the Danube river transport communications as an important economic connection 
between East and West, resulting in significant economic profits. The consequent increased intensity and liberalization of the navigational regime evoke risks such as accidents on ships carrying various types of cargo, including hazardous ones, environmental pollution and ecological disasters, loss of human life, etc. The considerable increase in smuggling, drug trafficking, illegal traffic of arms and people is also expected. All these reasons make the functioning of the respective state authorities significantly more difficult.

\section{Military factors}

Instead of having destabilizing role as in the recent past, the military factor was transformed into an essential guarantee for the security of the Black Sea region. Traditions determine the special role of the national Navies in the maritime areas of the region. Having functioning infrastructure and experience in coordination of various activities, Navies are leading institutions in regional security cooperation.

During the past few years, the relations among the Black Sea countries, and respectively among their Navies, register continuous progress. Annual multinational naval exercises, the constant exchange of delegations, and the exchange of information on various topics became routine.

Potentially, this cooperation can be additionally activated through the search of cooperative solutions of common problems, such as:

- $\quad$ Protection of the interests of the Black Sea countries in their respective and agreed maritime territories;

- Strengthening the control of navigation;

- Conduct of combined operations for rescue of human life, ships and aircraft in distress at sea;

- Countering smuggling and illegal traffic of people, drugs and arms at sea;

- Control of maritime environment protection and elimination of the consequences of oil spillages, industrial and other ecological hazards;

- Coordination of combined activities at sea.

The accomplishment and the effective management of these activities promote the necessity to set up a common system for control of navigation, exchange of information and data, and for combined management of crisis response, as well as for creation of a common database. 


\section{Organization of shipping by the Bulgarian Black Sea coast}

Before discussing potential cooperation, let me briefly explain the organization of control of shipping by the Bulgarian Black Sea coast. At the present stage, on the Bulgarian Black Sea coast there are two independent stationary systems for surveillance, control of navigation and maritime boundary control. The first one is operated by the Bulgarian Navy, and the second one - by the National Service "Border Police." Both systems include coastal visual and radar surveillance sites and traffic control stations. Currently, there is no specialized shipborne or airborne surveillance capability included. The systems work in parallel, periodically exchanging - at certain levels - information of various matters of mutual interest. Both systems interact also with the following organizations:

- $\quad$ State Marine Administration;

- General Bureau "Customs";

- The port of Varna;

- The port of Bourgas.

The organization is influenced by ongoing reforms in a number of sectors. ${ }^{2}$ Of particular importance is the demilitarization of the structures of the Ministry of the Interior, including the Border Guards Service - now Border Police, and the Ministry of Transportation. ${ }^{3}$ This necessitates urgent organizational arrangements and technical measures to solve the following problems:

1. Positioning of radar sites along the coast does not provide for full control of shipping;

2. The variety of radar and communications equipment hinders compatibility, and even interoperability among the units of the system;

3. The low level of automation in information processing and information exchange impedes adequate decision making, especially in rapidly changing situations.

To overcome these problems we plan to design and build up a unified automated system for control of shipping. We call this system "Ekran."4

The vision of the Bulgarian Navy calls for the creation of a national, automated radar system for control of navigation and protection of the sea borders.

\section{Ekran}

The system is intended to provide data and information necessary for the control of shipping in the littoral zone, straits, and channels, for protection of the sea borders, environmental protection, rendering assistance to vessels in distress, rescue of human 
life at sea, countering contraband and illegal traffic of drugs, people and arms at sea. The "Ekran" system will provide common operational picture, while the situation will be recorded and documented at control stations.

The system has to fulfill the following main tasks:

- Search, detection, identification, classification and tracking of surface objects (contacts);

- Automatic transmission of contact data and complete radar picture from every radar site to the control station;

- Automatic data processing, picture compilation and integrated display on digital maritime charts in a unified standardized coordinate system;

- Control and support of navigation in the littoral zone, straits, and channels;

- Support of rescuing human life, Search and Rescue (SAR) of vessels and aircraft in distress at sea;

- Documentation of surveillance data;

- Data transmission to the automated command and control system of the Navy, the State Maritime Administration, General Bureau "Customs," ports, etc.;

- Automatic transfer of data and picture from aircraft and ship-based surveillance radars;

- Real time data processing for up to 200 contacts;

- Compilation of radar and digital chart display;

- Initiation of security zones, borders, channels, navigation limits and marks, etc.;

- Connection to the surveillance system of the Air Traffic Control authorities.

The "Ekran" system will have the following structure and composition:

- 12-15 independent unmanned radar sites positioned from Dourankulak in the North to Rezovo in the South, to provide high density of surveillance. They will be organized in two areas - northern and southern;

- 4-6 control stations for each area: one for the Navy, for the National Service "Border Police," for the State Maritime Administration, for the General Bureau "Customs," etc.;

- Unified communications network for exchange of information and network management, as integral part of the "Ekran";

- Specialized airborne surveillance post capable of transferring data and surface picture to the land-based segments of the system. 
Our assessment is that the creation of such a system will meet the requirements of all concerned authorities and will provide for effective control of shipping, protection of sea borders, search and rescue operations, prevention of ecological disasters, countering contraband and drug trafficking.

According to preliminary plans, the development and the initial operational capability of a unified coastal system for control of navigation, having the described functions and structure, will create prerequisites for:

- Significant decrease of losses for Bulgaria caused by smuggling, illegal immigration and unsanctioned use of natural resources in the territorial waters and in the exclusive economic zone of Bulgaria;

- Shortening the time needed for SAR operations by 40-60 percent, that will lead to increased probability of rescuing people and craft in distress while reducing the expenses for such operations by 30-50 percent;

- Compared with the expenses for the present organization, the installation of a single type, reliable radar systems and means of communications will allow 30-40 percent savings of finance needed for maintenance and operation;

- Bulgaria will implement its international obligations, including those for the development of the global system for rescuing at sea GMDSS.

\section{Potential for cooperation among Black Sea countries}

The assessment of the Bulgarian Navy is that there is a considerable potential in the integration of the Bulgarian automated information system "Ekran" with similar systems of other Black Sea countries. The purpose of such integration of automated systems supporting naval activities, as well as activities of border and customs authorities and maritime administrations would be primarily focused on cooperative activities in border security and SAR.

We assume that the needs of the responsible authorities in other Black Sea countries are similar to the ones described in the previous section. Achieving effectiveness in the functioning of these agencies is possible only if the needed information with adequate quality is received in time. Furthermore, effectiveness is facilitated when these agencies receive information not only about contacts in the respective national Area of responsibility but, when feasible, from the Black Sea region as a whole.

Up to now, the collection of information for maritime contacts and its utilization by the competent authorities of the Black Sea countries have been accomplished only in the framework of their national surveillance systems. Basic disadvantage of this way of operation is the lack of information in a country for the traffic of vessels, which will visit other countries' ports or will just use the right of transit passage through its 
territorial waters. There is often lack of basic information, thus it is not possible to determine the port of origin and port of destination or initial and final ports of call of vessels, type of cargo, especially for vessels carrying hazardous cargo, etc. Such a lack hampers considerably control of shipping and rendering assistance to ships in distress at sea.

For example, a few years ago the Bulgarian Navy conducted unsuccessful search of a ship transporting particularly hazardous cargo, being reported to intent to dispose of it in close vicinity to Bulgarian territorial sea. Subsequently, we find out that Turkish authorities did not allow access of this vessel to the Black Sea. The timely availability of this information would have saved us significant resources and efforts.

In addition, there have been numerous occasions when international cooperation and mutual assistance have been needed in conducting search and rescue operations.

In order to overcome these disadvantages we propose to study the possibility of regular mutual exchange of information among the Navies of the Black Sea countries and to develop jointly a suitable model for cooperation. We understand that this is not a trivial task. Even for a single country, e.g. Bulgaria, the accomplishment of this complex task requires that a number of organizational and technical problems be solved at the level of Government. Nevertheless, we believe that when there is goodwill, the difficulties may be overcome, even though that may require considerable time and efforts.

It is necessary to reach an agreement among the respective state authorities of the Black Sea countries on the transfer of certain type and volume of information. This agreement has to regulate:

- Nature and volume of information to be transferred;

- Government structure that will prepare, send, receive and use the relevant information;

- Methods and channels of information exchange.

From the organizational point of view, it will be necessary to ${ }^{5}$ :

- Determine each country's agency that will be in charge of this project;

- Set up a collective authority to organize and control international cooperation activities and exchange of information;

- Work out the necessary regulating documents;

- Provide the needed financial and technical means.

Technically, it is necessary to solve the following issues: 
- To plan and set up the necessary communications networks, connecting the naval information systems of the participating countries and providing transfer of information;

- To ensure technical compatibility among the automated information systems of the Navies of the Black Sea countries;

- To standardize forms and documents for exchange of information;

- To set up an information database.

The commencement of these activities may be gradual, starting with the most essential - creation of a sound mechanism for coordination and exchange of information among existing systems. Next, we need either to continue with the adaptation of existing systems to provide interoperability or to approach jointly the creation of a unified automated information system of the Navies of the Black Sea countries.

\section{Conclusion}

Bulgaria, as one of the initiators for networking the naval information systems of Black Sea countries, is ready to take the initiative and to organize a meeting of a Working Group with representative for all interested countries. Initially, the Working Group would consider organizational and technical problems for the realization of the project. We believe it is possible to organize such a meeting in 2001 in Varna, Bulgaria.

I personally believe that the creation of a unified system for control and information exchange among Black Sea countries will contribute to the improvement of navigation safety in the Black Sea, will increase the operational effectiveness in the control of shipping, will improve the cooperation among our Navies and, as a result, will strengthen the confidence among the countries and the stability of the region. 


\section{Notes:}

1 This article is based on a presentation of the Chief of Staff of the Bulgarian Navy Vice Admiral Peter Petrov to the Third COMBLACKSEANAVMET (Istanbul, Turkey: 18-21 April 2000).

2 For a comprehensive analysis of the relation between defense reform and force modernization, and the Bulgarian experience in particular, the reader may refer to the article in this volume of Information \& Security by Todor Tagarev, "Prerequisites and Approaches to Force Modernization in a Transition Period."

3 Until 1999, the respective organizations of the two ministries were considered part of the Bulgarian Armed Forces. Although they were not subordinated to the Chief of the General Staff in peacetime, planning, operations, and modernization were coordinated more efficiently. The name translates literally as "Screen" or "Shield."

5 The article by Velizar Shalamanov, "C4ISR in Modernizing Security Sector in Bulgaria and South-Eastern Europe" in this volume provides comprehensive discussion on the cooperative C4ISR development and its role in promoting regional security.

Vice Admiral PETER PETROV is Chief of Staff of the Bulgarian Navy since 1998. He is 1974 graduate of the "N.Y. Vaptzarov" Naval Academy in Varna, Bulgaria, and 1982 graduate of the Naval Academy (Command and Staff College equivalent) in Sanct Petersburg, Russia. In 1995 Admiral Petrov graduated with distinction the Senior Officers' Course at "G.S. Rakovsky" Defense and Staff College in Sofia, Bulgaria. He has served in a variety of command positions in the Bulgarian Navy. In the 1997-1998 time period then Rear Admiral Petrov served as Deputy Chief of the General Staff of the Bulgarian Armed Forces. 